\title{
High-Efficiency Voltage Regulator and Stabilizer for Outdoor Lighting Installations
}

\author{
F. R. Blánquez, E. Rebollo, F. Blázquez \\ and C. A. Platero
}

\author{
P. Frías
}

\begin{abstract}
This paper presents a high performance system of regulation and stabilization of luminous flux for public street lighting installations. Its purpose is to reduce the luminous flux of the luminaries efficiently by reducing their voltage supply, resulting in the improvement of energy efficiency in the installation. The system is basically composed of electromagnetic components which provide robustness and high-performance to the device, as well as minimum maintenance requirements. However, the voltage regulation is based on the application of voltage steps. Aging studies of the luminaries have been carried out to analyze the impact of this discrete voltage regulation. A specific prototype of this voltage and stabilizer regulator have been in operation in a real outdoor lighting installation for more than one year.

Index Terms - voltage regulator, outdoor lighting, energy efficiency.
\end{abstract}

\section{NOMENCLATURE}

$V_{I} \quad$ Input voltage

$V_{L} \quad$ Load voltage

$V_{T 1 \text { prim }}$ Transformer 1 primary winding rated voltage

$V_{T 1 \text { sec }}$ Transformer 1 secondary winding rated voltage

$V_{\text {T2prim }}$ Transformer 2 primary winding rated voltage

$V_{T 2 s e c}$ Transformer 2 secondary winding rated voltage

$V_{\min } \quad$ Voltage stabilizer lower limit set point

$V_{\max } \quad$ Voltage stabilizer upper limit set point

$r_{1} \quad$ ratio of transformer 1

$r_{2} \quad$ ratio of transformer 2

\section{INTRODUCTION}

Energy efficiency and energy saving are nowadays priorities for any economy, and they can be achieved without affecting the dynamics of their activity, also enhancing the competitiveness of their production processes and reducing both emissions of greenhouse gases and energy losses. One area under study among the energy efficiency field is street lighting.

The energy consumption of street lighting in Europe (EU25) was over $35 \mathrm{TWh}$ in 2005, which accounts for $1.3 \%$ of the final electricity consumption in Europe. This consumption has negative environmental effects, such as carbon dioxide emissions and light pollution.

The potential saving in public lighting by using efficient technologies is really high [1],[2]. Currently there is a lack of implementation of energy efficient technologies and in many places the lighting levels used are much higher than recommended. In fact, in Spain, the existing legislation on this topic specifies that public outdoor lighting installations (street lighting, special lighting, decorative lighting and lighting of signs and neon lights) with an installed power exceeding $5 \mathrm{~kW}$ must be designed with particular devices to regulate the lighting level [3]. According to this Spanish rule, the lighting level control systems should be able to decrease up to $50 \%$ the emitted lighting flux of its value during peak hours, maintaining the uniformity of the light along the whole installation.

There are different types of lighting level control devices: 1) series inductive type ballasts for dual power level [4];2) power controlled electronic ballasts [5],[6]; and 3) regulators and stabilizers in the head of the line. The choice of the lighting level control system will be determined by several factors including the voltage variation of the lamp, the status of the main supply of the lamp, the lamp type or the number of hours of operation.

The main problem of using ballasts for dual power level is that these systems act locally, requiring an adjustment device attached to each of the individual charges and also a general control system to control all of them. This translates into a high initial investment as well as high demanding maintenance requirements. Certainly, these systems provide very accurate regulation, far from the real regulation requirements in street lighting. So this makes them too complex and expensive systems, not optimal for the use to which they are intended [7]. Moreover, most of the current systems used as stabilizers and regulators in lighting control are derived directly from voltage stabilizers based on power electronic. Because of the nonlinearity inherent in the semiconductor devices used in power electronic devices, the input current waveform will have some harmonic distortion and this will affect to the current total harmonic distortion (THD) of the network [8].

The device that is presented in this paper can be found in the group of electromagnetic regulators and stabilizers installed in header line, among the supply network and the line of lamps. This regulator and stabilizer has been designed according to the results of a previous design of a voltage regulator for rural networks [9].

The luminous flux control is reached by regulating the voltage level of the lamps that compose the street lighting 
installation. The key is that the luminous flux, the voltage and the power of the lamps vary proportionately. Thus, a reduction of $50 \%$ of output light implies a reduction of approximately $40 \%$ of the power consumed by the facility (depending on the type of lamp), with the energy savings and reduction of emissions to the atmosphere that it also entails. Due to the voltage regulation of the system presented is based on the aplication of voltage steps, aging tests have been carried out in order to verify that this discrete voltage regulation doesn't affect the life of the lamps.

Another important point to be considered is the frequent change in the level of voltage that occurs on a regular supply network. These oscillations are usually less than $7 \%$ of rated voltage of the network [10]. Because of its harmful effect on the lamps, there is a need of installing a stabilizer system in order to keep the voltage within preset margins. This avoids the lamp's shutdown / off when the supply voltage is lowered too far. The stabilizer system also maintains the energy saving scheme despite the significant increases of the supply voltage.

This paper presents a new voltage regulator and stabilizer that reduce the luminous flux efficiently by reducing the voltage supply. Section II presents the design of the voltage regulator, describing the power circuit and control circuit. The lamp performance test and aging test are described in section III and IV respectively. Section V presents the experience data related to a real installation where a prototype of the new regulator has been tested.

\section{Voltage Regulator AND Stabilizer. Principle OF OPERATION.}

This work provides an effective method of lighting regulation for outdoor lighting installations and, therefore, it presents an efficient procedure for saving electric energy. The system presented is characterized by the use of electromagnetic devices such as transformers and contactors. This is one of the main differences compared to current systems based on power electronic devices.

\section{A. Power circuit}

The power circuit of a one phase regulation and stabilization system consists of two subsystems in a series connection, the Stabilizer (a) and Regulator (b), shown in Fig. 1. The configuration of both subsystems is based on a two-winding transformer. Both stabilizer and regulator primary windings and the output voltage in each case, $V_{S}$ and $V_{L}$ are connected in series. These primary windings are also connected in parallel with their input voltage, $V_{I}$ and $V_{S}$.

The voltage Stabilizer (a) consists of a transformer (T1), directly fed from the network, $V_{I}$, in its primary winding. The secondary winding is installed in series with both the primary winding and the load, the regulation system in this case. The ratio of this transformer is designated as $r_{1}$.

A contactor $(\mathrm{C} 1)$ connects the system with the network, $V_{I}$. If this contactor is not energized, then $V_{S}=V_{I}$, and the stabilizer is in bypassed position. The stabilizer has also another contactor (C2) which allows the inversion of the

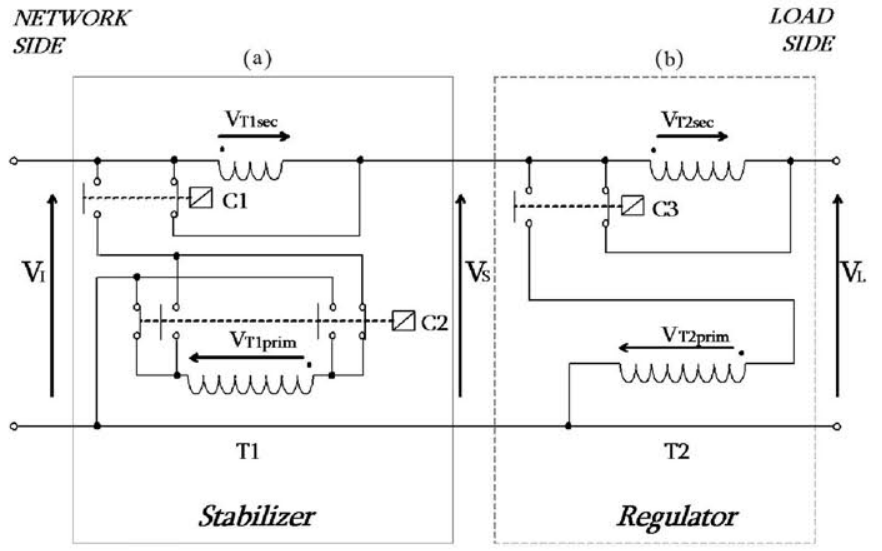

Fig. 1. Simplified scheme of a single phase Regulator-Stabilizer.

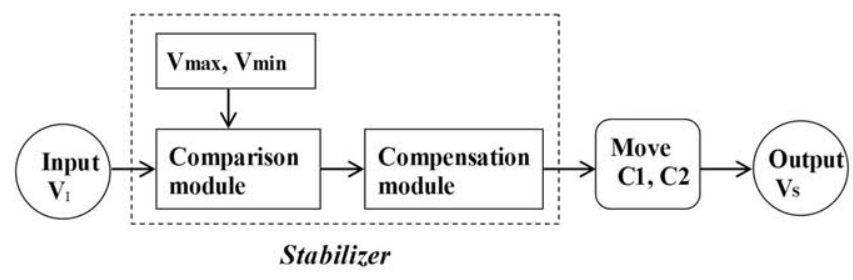

Fig. 2. Control system of the voltage stabilizer.

induced voltage polarity in the secondary winding by inverting the voltage polarity in the primary winding. Thus, the system can feed the load by adding a voltage step to the input voltage from the main network, as positive or negative value for $V_{t 1}$.

This setup provides three different voltage ranges that can be applied to the input of the regulator:

$$
\begin{array}{r}
V_{S}=V_{I} \\
V_{S}=V_{I}+V_{T 1 \mathrm{sec}} \\
V_{S}=V_{I}-V_{T 1 \mathrm{sec}}
\end{array}
$$

The lighting flux Regulator (b) is made, in a similar way as the previous stabilization system, by a transformer (T2), with ratio of $r_{2}$.

The main feature of this new configuration, as mentioned, is that the primary winding is fed directly from the output of the stabilizer $V_{S}$ or, failing that, from the network, $V_{I}$, while the secondary winding is connected in series with the primary winding and the load. Another contactor (C3) links the system with the installation and when it acts, it is applied to the lamp a step voltage reduction, $V_{T 2 s e c}$.

\section{B. Control circuit}

The control system of the Voltage Stabilizer (Fig. 2) consists of a voltage relay that is preset for operating in a voltage range between $V_{\min }$ and $V_{\max }$. These values represent $\pm 7 \%$ of rated voltage of the network, $V_{I}$. When the voltage $V_{I}$ remains within the preset voltage range $\left(V_{\min }, V_{\max }\right)$, the stabilization system is not involved and the regulation system is directly supplied by the network. 


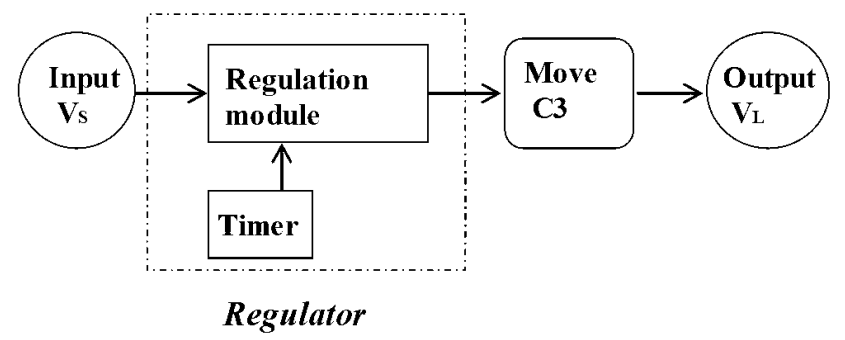

Fig. 3. Control system of the voltage regulator.

In the event that the voltage $V_{I}$ is not in the preset voltage interval $\left(V_{\min }, V_{\max }\right)$, the operating element (C1) is excited and the stabilization system keeps connected to the installation. In this case there are two options:

- In the event of $V_{I}>V_{\max }$, the switching element (C2) acts. The primary winding of the transformer (T1) is then fed by the supply network voltage, $V_{I}$, so that, in its secondary winding, it induces a voltage $\left(V_{I} / r_{1}\right)$, and the regulation system (b) is supplied with a voltage $V_{S}$, given by

$$
V_{S}=V_{I} \cdot\left(1-1 / r_{1}\right)
$$

- In the event of $V_{I}<V_{\min }$, the switching element (C2) acts. The transformer's (T1) primary winding is now fed by the supply network voltage, $V_{I}$, so that, in its secondary winding is now induced a voltage $\left(-V_{I} / r_{1}\right)$, and the regulation system (b) is fed with a voltage $V_{S}$, given in this case by

$$
V_{S}=V_{I} \cdot\left(1+1 / r_{1}\right)
$$

For the regulation system (Fig. 3), a preset sensor (time relay, astronomical clock, photoelectric sensor, etc.) gives the command to connect the regulation.

It causes the excitation of the operating element (C3). The performance of the operating element (C3) drives the regulation system. The primary winding of the transformer (T2) is now powered by the voltage $V_{S}$, the output voltage of the stabilization system. Then, in the secondary winding of the transformer, a voltage $V_{S} / r_{2}$ is induced, so the voltage in the lamps is $V_{L}$, given by

$$
V_{L}=V_{S} \cdot\left(1-1 / r_{2}\right)
$$

In case of the operating element (C3) is not energized, the regulation system does not get involved and the voltage level on the lamp is the stabilizer output voltage. In this case the regulator is in bypassed position. In Table I the lamp voltage level for each combination of operating elements state is summarized.

\section{Device Features}

The characteristics and configuration of the stabilization and control system make the described system an optimum system to meet the needs that an installation of street lighting requires, including:
TABLE I

COMPENSATION STEPS - LAMP VOLTAGE LEVEL - OPERATING ELEMENTS STATE (O: OPENED, C: CLOSED)

\begin{tabular}{c|ll|lll}
\hline \hline $\begin{array}{c}\text { Luminous } \\
\text { Flux }\end{array}$ & Supply Voltage $V_{I}$ & Lamps Voltage Level $V_{L}$ & $\mathrm{C} 1$ & $\mathbf{C} 2$ & $\mathbf{C 3}$ \\
\hline & $V_{\min }<V_{I}<V_{\max }$ & $V_{I}$ & & & \\
\hline & $V_{I}>V_{\max }$ & $V_{I} \cdot\left(1-1 / r_{1}\right)$ & $\mathrm{O}$ & $\mathrm{O}$ & $\mathrm{O}$ \\
& $V_{I<V_{\min }}$ & $V_{I} \cdot\left(1+1 / r_{1}\right)$ & $\mathrm{C}$ & $\mathrm{O}$ & $\mathrm{O}$ \\
& $V_{\min }<V_{I}<V_{\max }$ & $V_{I} \cdot\left(1-1 / r_{2}\right)$ & $\mathrm{C}$ & $\mathrm{C}$ & $\mathrm{O}$ \\
\hline $\begin{array}{l}\text { Reduced } \\
\text { flux }\end{array}$ & $V_{I}>V_{\max }$ & $V_{I} \cdot\left(1-1 / r_{2}\right) \cdot\left(1-1 / r_{1}\right)$ & $\mathrm{C}$ & $\mathrm{O}$ & $\mathrm{C}$ \\
\hline \hline
\end{tabular}

- High Performance: For a lamps line that demands a power designated $S(5)$, being typically $V=230 \mathrm{~V}$, the transformer used for the stabilizer system doesn't need to manage all this power, as other systems do. This is an autotransformer configuration, which allows working with a reduced size power transformer. Thus, for the stabilizer, the transformer's power should be about $S_{1}$ (6), and for the regulator, its transformer's power would be about $S_{2}(7)$, where $V_{T 1 \text { sec }}$ and $V_{T 2 \text { sec }}$ are much smaller than $V$, and thus $S_{1}$ and $S_{2}$ much smaller than $S$. This means that, unlike actual existing models, for the same functionality, this new system offers a considerable reduction in power losses, size, weight and levels of complexity.

$$
\begin{array}{r}
\quad S=V * I \\
S_{1}=V_{T 1 \text { sec }} * I \\
S_{2}=V_{T 2 \sec } * I
\end{array}
$$

- Discrete step voltage regulation: The discrete steps are obtained according to the supply network fluctuations in the connection point, and the admissible voltage reduction of the supply voltage of the lamps, which depends on the lamp type.

- Robust: It is a device typically installed outdoors, usually in difficult access areas. For greater reliability and easy maintenance, it is better to use electromechanical contactors than power electronics.

- Reliability: In addition to ensuring high reliability levels, in case of system failure the regulator is connected in bypassed position and this provides a continuous and uninterrupted energy supply for lighting.

- Low cost: Using serial voltage compensation instead of a full power converter reduces the device size and cost, increasing the efficiency notably.

- Versatility: The system is able to present one-phase or three-phase configurations. 


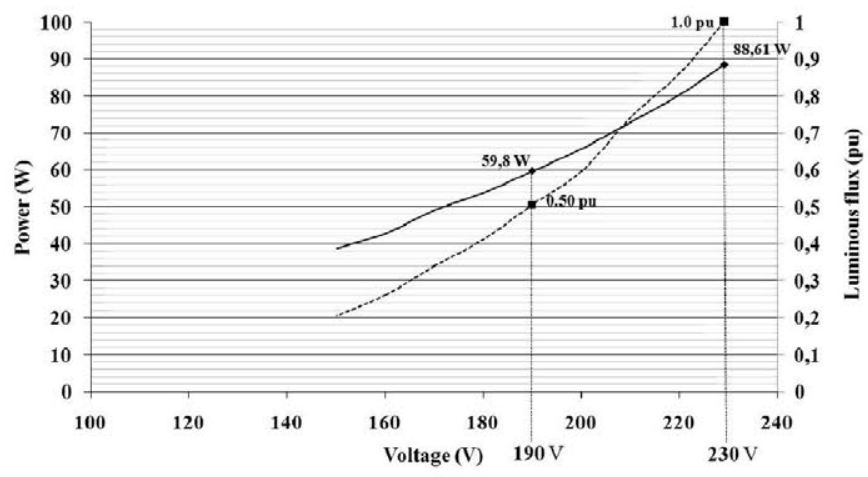

Fig. 4. H.P. Sodium optimal operating point.

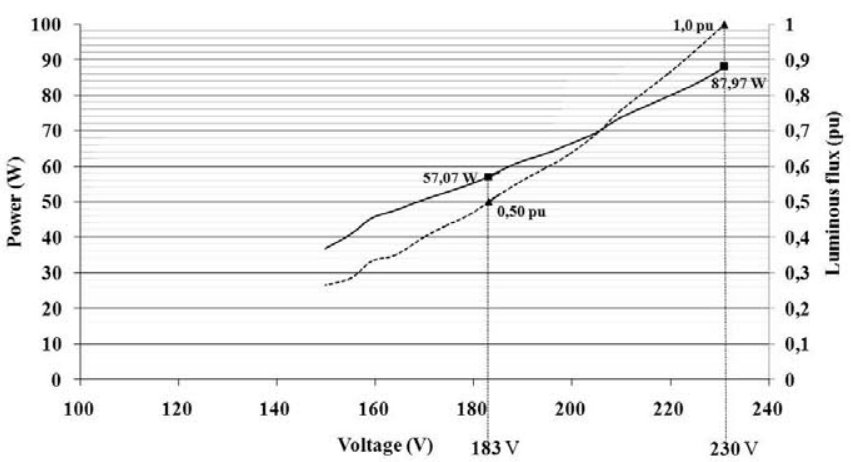

Fig. 5. Metal Halide optimal operating point.

\section{LAMP PERFORMANCE TEST.}

This system is designed for the optimization of public lighting installations, often using High Pressure Sodium or High Pressure Mercury Vapor discharge lamps type , Metal Halide, etc.

Each type of lamp allows a reduction in voltage limited by a minimum voltage level at which the lamp just switches off. Furthermore, the goal of reaching the mentioned $50 \%$ luminous flux reduction per lamp will require a different voltage reduction in each one due to the different properties of any type of lamp. Considering these conditions, a protocol test has been carried out in the laboratory to find the optimal operation condition (maximum allowable voltage reduction) for each type of lamp. By taking measurements of luminous flux for different voltage levels, we conclude the optimal level of voltage reduction.

Thus, in case of HP sodium lamps $(80 \mathrm{~W})$, we conclude that to achieve $50 \%$ reduction in luminous flux, it is necessary to reduce the lamp voltage in $40.73 \mathrm{~V}$, achieving energy savings of $29.24 \mathrm{~W}$ per lamp, $33 \%$ of the power consumed without the regulation system. The complete test results are shown in Fig. 4

In the same way, metal halide lamps $(70 \mathrm{~W})$ reach a reduction of $50 \%$ luminous flux by reducing voltage in 36.89 $\mathrm{V}$, achieving energy savings of $30.89 \mathrm{~W}, 35.11 \%$ of the consumed power. The complete test results are shown in Fig. 5. In table II the optimal working point and energy saving for
TABLE II

LAMPS WORKING POINT FOR 50\% OF FLUX REDUCTION

\begin{tabular}{ccc}
\hline \hline Lamp & Optimal $\Delta \mathbf{U}(\mathbf{V})$ & Energy saving (\%) \\
\hline H. P. Sodium & 40,73 & $33,13 \%$ \\
Metal Halide & 36,89 & $35,11 \%$ \\
\hline \hline
\end{tabular}
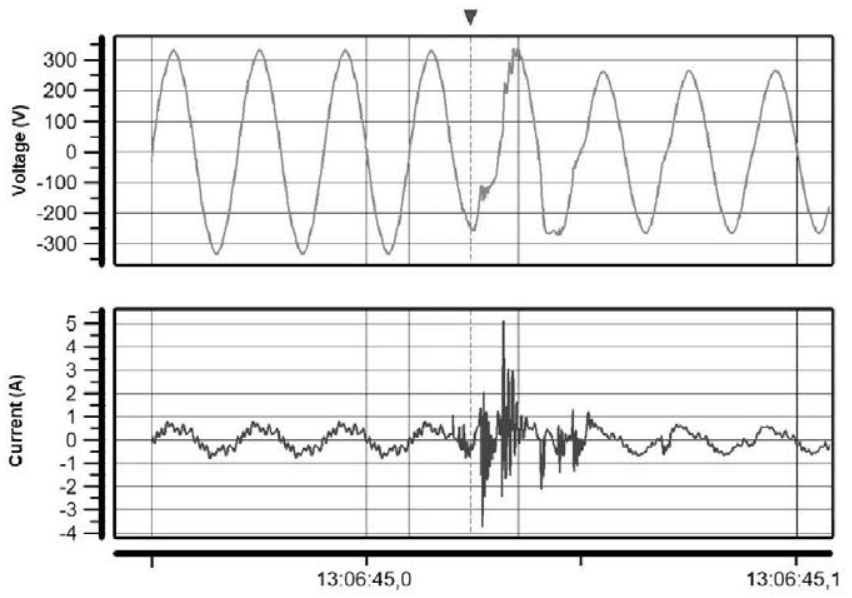

Fig. 6. Transient study during voltage switching.

each technology is summarized.

It has been verified that the voltage reduction is associated with a reduction in luminous flux and energy consumption, but different for each lamp. As noted, Spanish rules restrict the flux reduction up to $50 \%$ in the hours in which the regulation system operates. In the particular case of HP sodium lamps, the voltage reduction needed to achieve the $50 \%$ of flux reduction is 40.73 , far from the $47 \mathrm{~V}$ of the lamp threshold. For any flux lighting reduction, the results shown in Fig. 4 and Fig. 5 are useful in order to design the voltage regulator.

In case of fluorescent lamps (less common lights in public lighting facilities) the reduction of luminous flux and power is milder than with the other lamps, so it is very difficult to obtain the $50 \%$ of flux reduction by reducing the supply voltage and avoiding the own fluorescent lamp threshold. For this type of lamps a voltage reduction of $40 \mathrm{~V}$ only implies a reduction of $26.06 \%$ of the luminous flux.

\section{EXPERIMENTAL TEST. LAMP AGING TEST.}

The voltage switching applied to the lamp by this new regulation system, without any element of an electronic nature, is sharp. This fact is presented as one of the main drawbacks of the system because it could accelerate in the aging process of the lamp. The voltage and current variation detected in the lamp due to the performance of the controller is shown in the Fig. 6.

After conducting numerous surveys, we found no voltage peak too dangerous on the lamp, and at no time did the lamp come to turn off because of these switches. During the tests no major problem has been found. A specific test has also been carried out to observe the behavior of light to these long-term actions. In a laboratory several test have taken place 


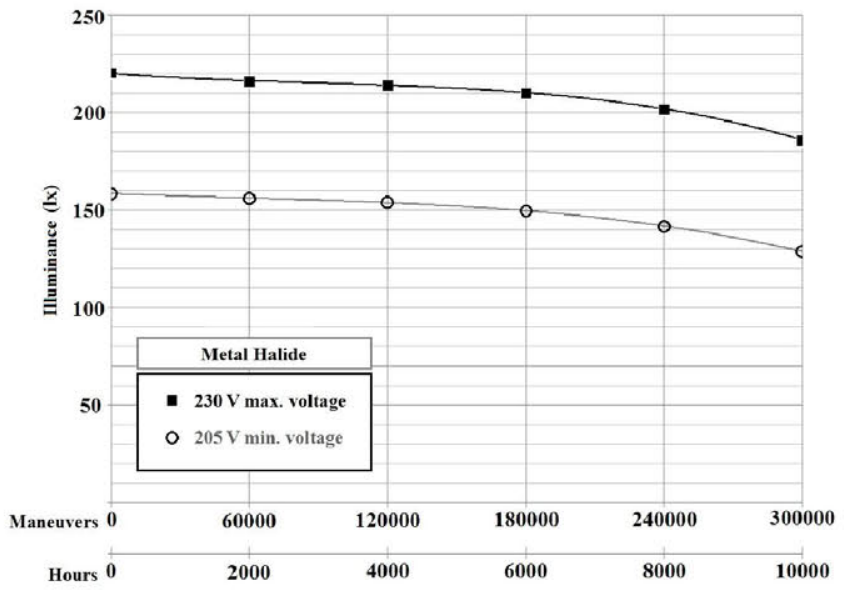

Fig. 7. Metal Halide lamp aging test.

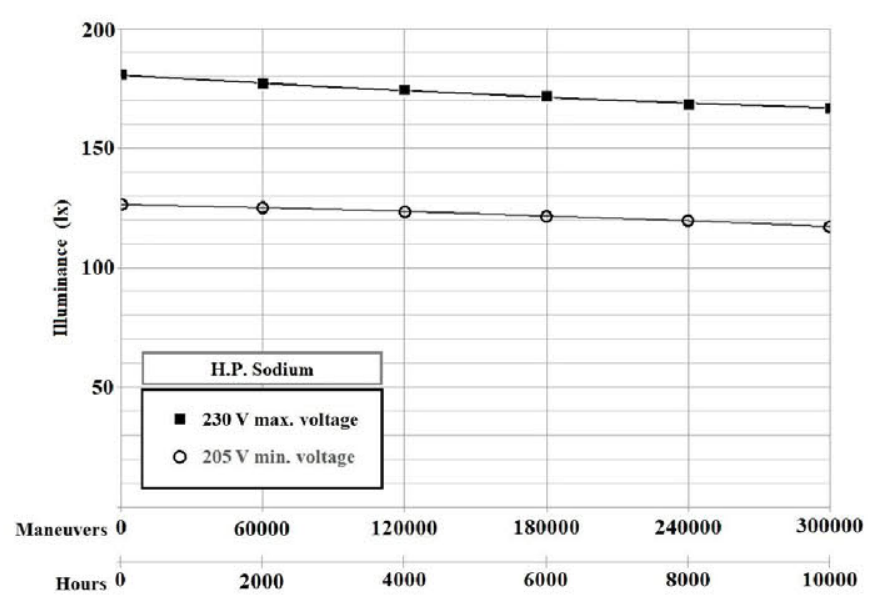

Fig. 8. H. P. Sodium lamp aging test.

by feeding different types of lamps through a stabilizer and regulator device as the one presented in this paper, during a relevant time period, so the lamps have suffered much higher amount of operations that suffer throughout their life in a line of street lighting.

\section{A. Lamp Features.}

The test detailed here has been performed for both metal halide and HP sodium lamp. According vendor-features, its life is between 12,000 to $16,000 \mathrm{~h}$ for the metal halide lamp and between 8,000 and $12,000 \mathrm{~h}$ for the HP sodium lamp. As the lamp usually remains on an average of 8 hours and suffers two performances of the regulator per day, it is estimated that, throughout its whole life the lamp will suffer around 3,500 maneuvers, if only the regulation system works.

\section{B. Test conditions.}

The lamp has remained constantly switched on, to the continuous operation of the regulation system by introducing this operation every 2 minutes (established after a study period of warming and stabilization of light output by the lamp).

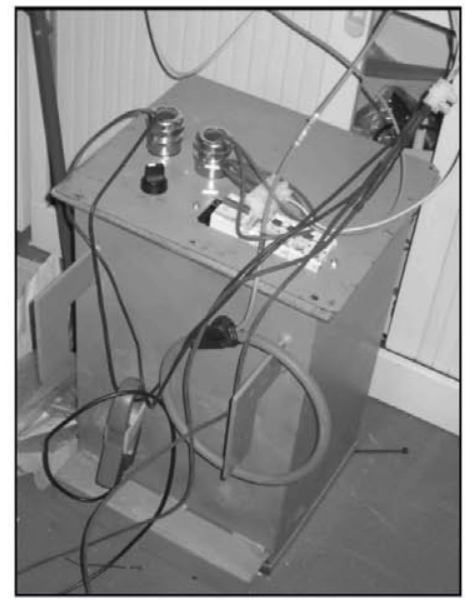

Fig. 9. Voltage stabilizer and regulator prototype.

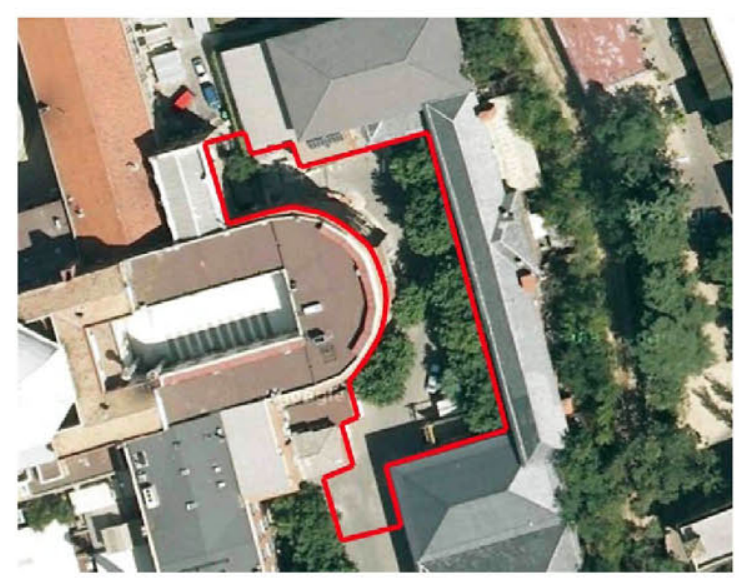

Fig. 10. Emplacement of the real studied installation.

\section{Current status of trial.}

At the end of the test, the lamp had been tested for approximately 10,000 hours, which means about 300,000 maneuvers. The luminous flux level and its variation have been registered during the test duration. In Fig. 7 and Fig. 8 are shown the illuminance variation during the test of a metal halide lamp and a HP sodium lamp, respectively. This variation is negligible despite the introduction of the regulation system. Therefore, we can conclude that the results of these tests were satisfactory and it can be said that the performance of the presented system does not affect or prejudice the normal operation of the lamps.

\section{REAL OUTDOOR LIGHTING INSTALLATION.}

A prototype (Fig. 9) of the luminous flux regulator presented in this paper has been in operation for more than one year. The developed prototype has 2 transformers. First, a two-winding single-phase transformer (V 230-25) and $3000 \mathrm{VA}$ of power for the voltage regulator, and second, a two-winding singlephase transformer (V 230-8) and 960 VA of power for the voltage stabilizer transformer. The operation of the regulator system attaches a fixed voltage reduction of $25 \mathrm{~V}$ to the lamps, 


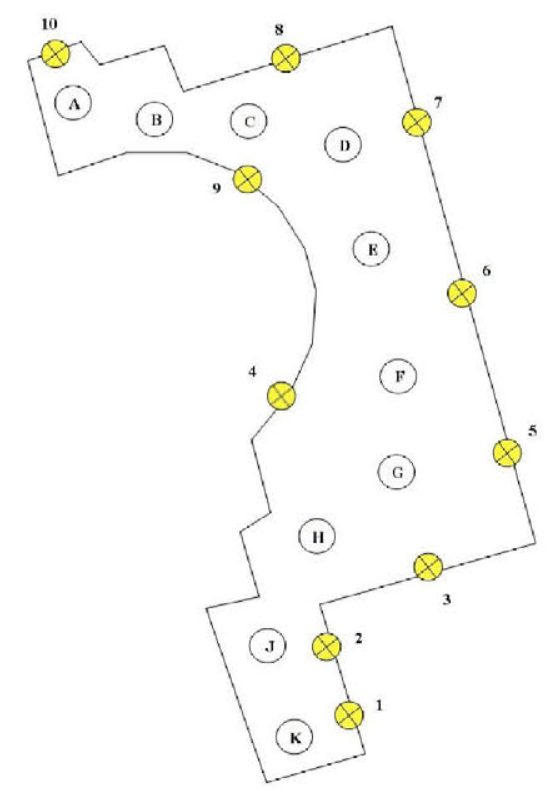

Fig. 11. Real lighting line and measuring points.

TABLE III

ILLUMINANCE REDUCTION

\begin{tabular}{c|cc|c}
\hline \hline Point & \multicolumn{2}{|c|}{ Illuminance (Ix) } & Illuminance \\
& Regulator OFF & Regulator ON & reduction (\%) \\
\hline A & 5.21 & 4.19 & 22.40 \\
B & 5.56 & 4.38 & 21.22 \\
C & 4.96 & 3.58 & 27.82 \\
D & 8.65 & 6.33 & 26.82 \\
F & 9.4 & 6.84 & 27.23 \\
G & 3.69 & 3.09 & 16.26 \\
H & 4.24 & 3.00 & 29.09 \\
I & 5.81 & 4.03 & 30.63 \\
J & 13.1 & 9.23 & 29.54 \\
K & 10.6 & 6.9 & 34.90 \\
\hline \hline
\end{tabular}

while the stabilizer systems applies an step of $\pm 8 \mathrm{~V}$ to the lamps.

Besides the design and the aging tests, the described prototype has been installed in a real street lighting installation in order to evaluate the operation of the device.

\section{A. Installation Data}

The lighting installation which has been chosen is located in the car park of the Escuela Técnica Superior de Ingenieros Industriales in Madrid (Fig. 10). The light line is composed by 10 lamps , metal halide, with a power of $2800 \mathrm{~W}$ supplied to the whole line. The proposed device was easily set up between the network and the lamps line. As described, the system had been set in order to reduce the lamp voltage $25 \mathrm{~V}$ when the regulator would act and $\pm 8 \mathrm{~V}$ when the voltage stabilizer would act.

\section{B. Luminous flux control}

The light intensity in several points over the studied area (Fig. 11) has been checked after the regulator act to keep
TABLE IV

Voltage Regulator AND Stabilizer Data

\begin{tabular}{cccc}
\hline \hline Stabilizer Transformer & Voltage & Current & Power \\
\hline Primary & $230 \mathrm{~V}$ & $4.18 \mathrm{~A}$ & $960 \mathrm{VA}$ \\
Secondary & $8 \mathrm{~V}$ & $120 \mathrm{~A}$ & $960 \mathrm{VA}$ \\
Non load losses & & & $19.2 \mathrm{~W}$ \\
Load losses & & & $76.8 \mathrm{~W}$ \\
\hline Regulator Transformer & Voltage & Current & Power \\
\hline Primary & $230 \mathrm{~V}$ & $13.04 \mathrm{~A}$ & $3000 \mathrm{VA}$ \\
Secondary & $25 \mathrm{~V}$ & $120 \mathrm{~A}$ & $3000 \mathrm{VA}$ \\
Non load losses & & & $25.1 \mathrm{~W}$ \\
Load losses & & & $104 \mathrm{~W}$ \\
\hline Regulation Step & & & \\
\hline S1 & & & $-25 \mathrm{~V}$ \\
S2 & & $\pm 8 \mathrm{~V}$ \\
S3 & & $-25 \mathrm{~V} \pm 8 \mathrm{~V}$ \\
S4 & &
\end{tabular}

TABLE V

VOLTAGE AND CURRENT REDUCTIONS AND ENERGY SAVINGS IN THE REAL INSTALLATION

\begin{tabular}{lccc}
\hline \hline & $\begin{array}{c}\text { Regulator } \\
\text { OFF }\end{array}$ & $\begin{array}{c}\text { Regulator } \\
\text { ON }\end{array}$ & $\begin{array}{c}\text { Reduction } \\
(\%)\end{array}$ \\
\hline Voltage (V) & 232.2 & 207.9 & 10.47 \\
Current (A) & 13.72 & 10,62 & 22.59 \\
Active Power (W) & 2,806 & 2,080 & 25.87 \\
Apparent Power (VA) & 3,171 & 2,230 & 29.68 \\
\hline \hline
\end{tabular}

TABLE VI

EFFICIENCY (\%)@POWER FACTOR 1

\begin{tabular}{c|cccc}
\hline \hline Load (p.u.) & $\mathbf{0 . 2 5}$ & $\mathbf{0 . 5 0}$ & $\mathbf{0 . 7 5}$ & $\mathbf{1}$ \\
\hline$S 1$ & 99.92 & 99.96 & 99.97 & 99.98 \\
$S^{\prime} 2$ & 99.47 & 99.59 & 99.57 & 99.52 \\
$S 3$ & 99.64 & 99.72 & 99.69 & 99.65 \\
$S 4$ & 98.98 & 99.21 & 99.16 & 99.04 \\
\hline
\end{tabular}

TABLE VII

EFFICIENCY (\%) @ POWER FACTOR 0.8

\begin{tabular}{c|crrc}
\hline \hline Load (p.u.) & $\mathbf{0 . 2 5}$ & $\mathbf{0 . 5 0}$ & $\mathbf{0 . 7 5}$ & $\mathbf{1}$ \\
\hline$S 1$ & 99.90 & 99.95 & 99.97 & 99.98 \\
$S 2$ & 99.33 & 99.49 & 99.47 & 99.39 \\
$S 3$ & 99.55 & 99.64 & 99.62 & 99.56 \\
$S 4$ & 98.72 & 99.01 & 98.95 & 98.81 \\
\hline \hline
\end{tabular}

the limits established by the standards. It means that during the actuation of the regulator the luminous flux doesn't have to be reduced more than the $50 \%$ of the flux in normal conditions. This point is achieved by the system. The luminous flux measured in the measuring points during the test and the luminous flux reduction is summarized in Table III

\section{Energy saving and losses in the device.}

In Table IV the technical data of the regulator and stabilizer prototype is summarized. It has to be considered that the voltage stabilizer and regulator can manage up to $120 \mathrm{~A}$, so it is oversized compared to the lighting installation in where it is in operation. Table V shown the reduction of the voltage, current and power, considering only the operation of the regulator. The energy consumption is reduced by 726 $\mathrm{W}$, which represent more than the $25 \%$ of the total energy 
consumption. The energy saving is remarkable.

The efficiency of the prototype has been tested in the laborarory. Several tests have been carried out with different loads at power factor 1 and power factor 0.8 . The results of the efficiency tests are shown in Table VI and Table VII, where

S1 Bypassed position

S2 Regulator connected

S3 Stabilizer connected

S4 Regulator and Stabilizer connected

\section{Energy saving forecast.}

The lights are switched on for 10 hours a day, it would represent a consumption of $10,220 \mathrm{kWh}$ a year. The regulator is set up in order to operate during the less occupation hours, 6 hours a day. The consumption is reduced till $8,600 \mathrm{kWh}$, measured last year. It means an energy saving of more than $1,600 \mathrm{kWh}$ a year.

\section{CONCLUSION}

The stabilizer-regulator system presented in this paper incorporates some important technical advantages that makes it ideal for use in street lighting installations:

- The configuration of the system can supply power for lamps between two voltage levels, as well as offset the frequent voltage fluctuations in the lamp.

- The system does not accelerate the aging process of the lamps as demonstrated experimentally.

- A single device can adjust all the lamps in a single line between two voltage levels without an individual control device for each lamp.

- It is based on the use of electromagnetic character elements, which gives it great robustness and has minimal maintenance requirements.

- The device manufacturing process would be simple, economical and it does not require a high specialist labor.

Experimental data obtained from the operation of the stabilizer-regulator in a real lighting facility have shown its reliability and high performance.

\section{ACKNOWLEDGMENT}

The authors wish to acknowledge the technical support of Norma García. The design of the voltage Stabilizer and Regulator presented is this paper is under patent P201000509, October 27th 2011, "High efficiency luminous flux regulator for lighting installations".

\section{REFERENCES}

[1] Intelligent Energy Europe, "Guide for energy efficient street lighting installations," European Commission - Executive Agency for Competitiveness \& Innovation (EACI), 2007.

[2] Intelligent Energy Europe, "Project Report. Intelligent Road and Street lighting in Europe," European Commission - Executive Agency for Competitiveness \& Innovation (EACI), 2008.

[3] RD 1890/2008, de 14 de noviembre, por el que se aprueba el Reglamento de eficiencia energética en instalaciones de alumbrado exterior y sus Instrucciones técnicas complementarias EA-01 a EA-07, B.O.E., Nov. 19, 2008, Spain [Online], pp.46019. Available: http://www.boe.es
[4] Wei Yan and S.Y.R. Hui, "Dimming Characteristics of Large-scale HighIntensity-Discharge (HID) Lamp Lighting Networks using to EnergySaving Power station System" in Proc. IEEE Industry Applications Conference, 2006, Vol. 3, pp. 1090-1098.

[5] Wei Yan and S. Y. Hui, "An analysis into the dimming control and characteristic of discharge lamps," IEEE Trans. Power Electronics., Vol. 20, Issue 6, pp. 1432-1440, Nov. 2005

[6] S. Chen, B. Mulgrew, and P. M. Grant, "Practical evaluation of dimming control methods for electronic ballasts," IEEE Trans. Power Electronics., Vol. 21, Issue 6, pp. 1769-1775, Nov. 2005

[7] H. S.-H. Chung, Ngai-Man Ho, Wei Yan, Pok Wai Tam and S.Y Hui, "Comparison of Dimmable Electromagnetic and Electronic Ballast Systems-An Assessment on Energy Efficiency and Lifetime," IEEE Trans. Industrial Electronics., Vol. 54 , Issue 6, pp. 3145-3154, Dec. 2007

[8] E. Bompard, E. Carpaneto, G. Chicco, P. Ribaldone and C. Vercellino, "The impact of public lighting on voltage distortion in low voltage distribution systems," IEEE Trans. Power Delivery., vol.16, Issue 4, pp. $752-757$, Oct 2001

[9] P. Frías, C. A. Platero, D. Soler and F. Blázquez, "High-Efficiency Voltage Regulator for Rural Networks," IEEE Trans. Power Delivery., vol.25, Issue 3, pp. $1666-1672$, July 2010

[10] RD 1955/2000 de 1 de diciembre por el que se regulan las actividades de transporte, distribución, comercialización, suministro y procedimientos de autorización de instalaciones de energía eléctrica, B.O.E., Dec. 27, 2000, Spain. [Online]. Available: http://www.boe.es 